\title{
Quality versus queasy: neurokinin 1 receptor antagonist use in moderately emetogenic chemotherapy
}

\author{
Jayan Nair, MD, ${ }^{a}$ Brendan F Curley, DO, MPH, Richard Fong, PharmD, Jimmy Hwang, \\ $\mathrm{PhD},{ }^{\mathrm{c}}$ and Michael Byrne, $\mathrm{DO}^{\mathrm{d}}$
}

${ }^{a}$ TMH Cancer Center, Tallahassee, Florida; ${ }^{b}$ Arizona Center for Cancer Care, Scottsdale, Arizona; 'UCSF Helen Diller Family Comprehensive Cancer Center, San Francisco, California; and Division of Hematology and Medical Oncology and VanderbiltIngram Comprehensive Cancer Center, Nashville, Tennessee

Background The American Society of Clinical Oncology (ASCO) launched the Quality Oncology Practice Initiative (QOPI) program in 2010 to promote quality cancer care. The association has subsequently influenced the use of neurokinin 1 (NK-1) receptor antagonists through articles published in peer-reviewed publications and its Choosing Wisely campaign.

Objective To explore the rationale behind the use of NK-1 receptor antagonists in clinical practice.

Methods We distributed an anonymous 12-question online survey to 650 medical oncologists in 5 states, inquiring about their use of these agents. A total of 155 responses were analyzed.

Results QOPI-certified physicians were significantly more likely than noncertified physicans to use NK-1 receptor antagonists with moderately emetogenic regimens, including weekly cisplatin for head and neck cancer $(82.6 \%$ vs $27.0 \%$, respectively; $P<.001)$, cervical and bladder cancer (81.4\% vs $32.7 \%, P<.001)$, and with CHOP (cyclophosphamide, hydroxydaunorubicin, oncovin, prednisone) with or without rituxinab in lymphoma (81.4 vs $17.3 \%, P<.001)$. The majority of $Q O P I$-certified physicians reported using these agents for the sole purpose of maintaining QOPI certification (80.0\%-86.0\%). Certified physicians were also significantly more likely to appropriately prescribe NK-1 antagonists with highly emetogenic chemotherapy.

Limitations Responder bias; short survey that precludes detailed analysis; small sample size may limit generalizability to the field of medical oncology.

Conclusion Our data demonstrate that providers in QOPI-certified practices are significantly more likely than those in noncertified practices to prescribe NK-1 receptor antagonists. Certified physicians report that satisfying ASCO-QOPI requirements is their primary motivation for offering these agents.

$\mathrm{T}$ he majority of patients treated with systemic chemotherapy will experience some form of toxicity during their treatment course. A significant percentage of those individuals will experience nausea and/or vomiting, which may provoke anxiety and reduce patient satisfaction with therapy and care and patient quality of life. ${ }^{1}$ In our current chemotherapy armamentarium, platinum-based agents, particularly cisplatin, are among the most highly emetogenic. In recognition of this, Hesketh and colleagues ranked high-dose cisplatin $(\geq 50 \mathrm{mg} /$ $\mathrm{m}^{2}$ ) in the highest tier (level 5) when they stratified chemotherapies by emetogenic risk. ${ }^{2}$ Agents in level 5 are associated with a $>90 \%$ risk of emesis. At doses of less than $50 \mathrm{mg} / \mathrm{m}^{2}$, cisplatin is in level 4 with an emesis frequency of $60 \%-90 \% .^{2}$ In 1999 , the American Society of Clinical Oncology (ASCO) introduced its first antiemetic clinical practice guide- lines. ${ }^{3}$ Through 2 subsequent iterations, cisplatin has consistently remained in the highest emetic risk category regardless of the selected dose. ${ }^{4,5}$ Although prophylactic 5-hydroxytryptamine (5-HT3) antagonists and corticosteroids were initially recommended for patients in this high-risk category, updated guidelines from 2006 and 2011 recommend the addition of the neurokinin 1 (NK-1) receptor antagonist aprepitant that had been FDA approved since 2003..$^{3-5}$ ASCO added combinations of anthracyclines and cyclophosphamide to this high-risk category in 2011 and urged providers to also provide prophylactic NK-1 receptor antagonists to these patients. ${ }^{5}$

In parallel with its most recent antiemetic practice guidelines, ASCO launched the Quality Oncology Practice Initiative (QOPI) program in 2010. The purpose of the program is to promote practice improvement and increase the effectiveness of cancer

Accepted for publication April 19, 2016. Correspondence: Jayan Nair, MD; jayan.nair@tmh.org. Disclosures: The authors report no disclosures or conflicts of interest. JCSO 2016;14:255-260. @2016 Frontline Medical Communications. doi: 10.12788/jicso.0274. 


\begin{tabular}{|c|c|c|c|c|}
\hline Reference & $\begin{array}{c}\text { Regimen, } \\
\text { dose+dosage, n }\end{array}$ & Disease & Any grade, $\%$ & Grade $3 / 4, \%$ \\
\hline $\begin{array}{l}\text { Coiffier }{ }^{11} \\
\text { Lenz }^{12}\end{array}$ & $\begin{array}{l}\text { CHOP } \\
197 \\
160\end{array}$ & Lymphoma & $44-48$ & $6-8$ \\
\hline $\begin{array}{l}\text { Coiffier }{ }^{11} \\
\text { Lenz }^{12}\end{array}$ & $\begin{array}{c}\mathrm{R}-\mathrm{CHO} \\
202 \\
62\end{array}$ & Lymphoma & $42-45$ & 4 \\
\hline Valle ${ }^{13}$ & $\begin{array}{c}\text { Cis, } 25 \mathrm{mg} / \mathrm{m}^{2} \\
2 \text { wk on, } 1 \text { wk off } \\
204\end{array}$ & Biliary & NR & 9 \\
\hline Gupta $^{14}$ & $\begin{array}{c}\text { Cis, } 30 \mathrm{mg} / \mathrm{m}^{2} \\
\text { weekly } \\
264\end{array}$ & $\mathrm{H}+\mathrm{N}$ & NR & 3.4 \\
\hline Rose $^{15}$ & $\begin{array}{c}\text { Cis, } 40 \mathrm{mg} / \mathrm{m}^{2} \\
\text { weekly } \\
253\end{array}$ & Cervical & 60 & 12 \\
\hline Hagan $^{16}$ & $\begin{array}{c}\text { Cis, } 20 \mathrm{mg} / \mathrm{m}^{2} \\
\text { days } 1-3 \\
35\end{array}$ & Bladder & NR & 11 \\
\hline
\end{tabular}

$\mathrm{CHOP}$, cyclophosphamide, doxorubicin, vincristine, and prednisone; $\mathrm{Cis}$, cisplatin; $\mathrm{H}+\mathrm{N}$, head and neck, NR, not reported; $\mathrm{R}-\mathrm{CHOP}, \mathrm{CHOP}+$ rituximab

care in addition to increasing accountability among practitioners. ${ }^{6}$ Since its inception, more than 250 academic and community-based practices in the United States have completed the process and earned QOPI certification. ${ }^{7}$ During the spring 2012 QOPI cycle, a QOPI metric specifically addressed the use of aprepitant or fosaprepitant prophylaxis with "high emetic risk chemotherapy" (Symptom 28), signaling its importance to the provision of quality cancer care. ${ }^{8}$ Also in 2013, the ASCO Choosing Wisely campaign encouraged health care practitioners to be judicious with costly antiemetics to improve the cost effectiveness of cancer care. In the discussion, emphasis is placed on the additional cost and toxicity of these agents. Providers are encouraged to limit their use to circumstances in which chemotherapy with "high potential ... for severe and/or persistent nausea and vomiting" is used. ${ }^{9}$

Aprepitant and fosaprepitant, are oral and intravenous NK-1 receptor antagonists, respectively. Both are moderate inhibitors of CYP3A4 and interact with commonly used medications metabolized through the CYP3A4 pathway, such as apixaban and diltiazem. In addition, prescribers must be cognizant of known interactions with corticosteroids, some anthracyclines, and tyrosine kinase inhibitors, which are frequently used in chemotherapy regimens. ${ }^{10}$ Although the toxicity of these drugs as single agents is difficult to assess, fatigue, constipation, and weakness are attributed to their use..$^{10}$ Finally, the addition of these agents to prevent nausea and vomiting increases health care costs. The average wholesale price for a 3-day course of aprepitant is $\$ 597.81$; a single dose of fosaprepitant is $\$ 308.35$. $^{10}$ If these agents are used pre-emptively with all cycles, the additional cost of treatment can soar to thousands of dollars.

We reviewed the primary literature to better understand the emetogenic risk of regimens that contain cisplatin or a combination of doxorubicin and cyclophosphamide. The total incidence (all grades) of nausea and vomiting ranged from $42 \%-72 \%$, whereas the incidence of grade $3 / 4$ nausea was $3.4 \%-12 \%$ (Table). ${ }^{11-16}$ The only study to report on prophylactic antiemetics was one in which cisplatin $30 \mathrm{mg} / \mathrm{m}^{2}$ was used in patients with head and neck cancer. ${ }^{14}$ The patients received intravenous ondansetron 16 $\mathrm{mg}$ and dexamethasone $16 \mathrm{mg} 30$ minutes before chemotherapy. Based on these data, we questioned whether the widespread use of NK-1 receptor antagonists is clinically justified given the additional cost, toxicity, and drug interactions. We hypothesized that the prescribing patterns of oncologists are heavily influenced by the current ASCO and QOPI guidelines. We surmised that practitioners are using these agents to obtain QOPI certification, a mark of quality, rather than based on their clinical judgment. To answer this research question, we performed an online, survey-based assessment.

\section{Methods}

We designed and administered an anonymous, 12-question, online survey to better understand the prescribing habits of medical oncologists as they pertain to NK-1 receptor antagonists (Figure 1). Survey responses were in a dichotomous Yes/No format. For questions pertaining to NK-1 receptor antagonist use with chemotherapy regimens, respondents 


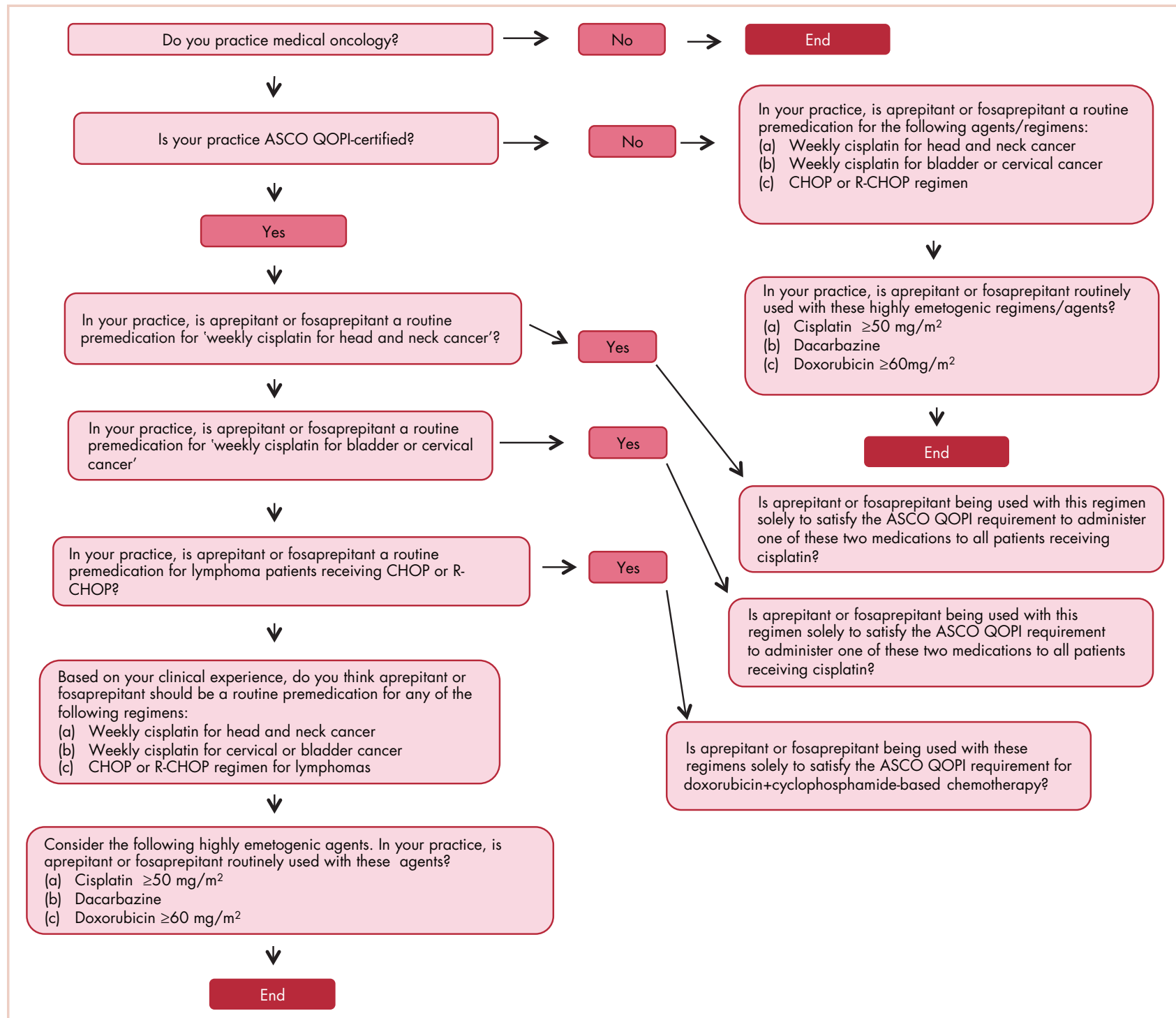

FIGURE 1 The online questionnaire used in the study.

ASCO, American Society of Clinical Oncology; CHOP, cyclophosphamide, hydroxydaunorubicin, oncovin, and prednisone; QOPI, Quality Oncology Practice Initiative; R-CHOP, rituximab + CHOP

were permitted to answer Not Applicable if they did not prescribe that regimen in their practice. The survey was sent to academic and community-based medical oncologists in northern California, Arizona, Minnesota, North Dakota, and South Dakota without respect to QOPI certification. A total of 650 practitioners were polled.

For the purposes of this study, and because of the Hesketh classification, we refer to cisplatin doses of $<50$ $\mathrm{mg} / \mathrm{m}^{2}$ and a cyclophosphamide-plus-anthracycline combination with doxorubicin dose $\leq 50 \mathrm{mg} / \mathrm{m}^{2}$ as moderately emetogenic.

In our survey, health care providers from QOPI-certified practices were asked whether they prescribed prophylactic NK-1 receptor antagonists for moderately emetogenic reg- imens, such as weekly cisplatin (for head and neck cancer, or bladder and cervical cancers) and when cyclophosphamide is used in combination with an anthracycline, as in cyclophosphamide, doxorubicin, vincristine, and prednisone (CHOP) without rituximab or with rituximab ( $\mathrm{R}-\mathrm{CHOP})$. Those who answered affirmatively were asked whether their motivation was compliance with the ASCO guidelines and subsequent QOPI certification. Next, we asked these providers whether, based on their clinical experience and judgment, they thought that NK-1 receptor antagonists should be used in the setting of weekly cisplatin or with $\mathrm{CHOP} /$ R-CHOP. Finally, practitioners were asked whether they routinely prescribed these agents with the highly emetogenic chemotherapy regimens: cisplatin $\geq 50 \mathrm{mg} / \mathrm{m}^{2}$, doxo- 


\section{Original Report}

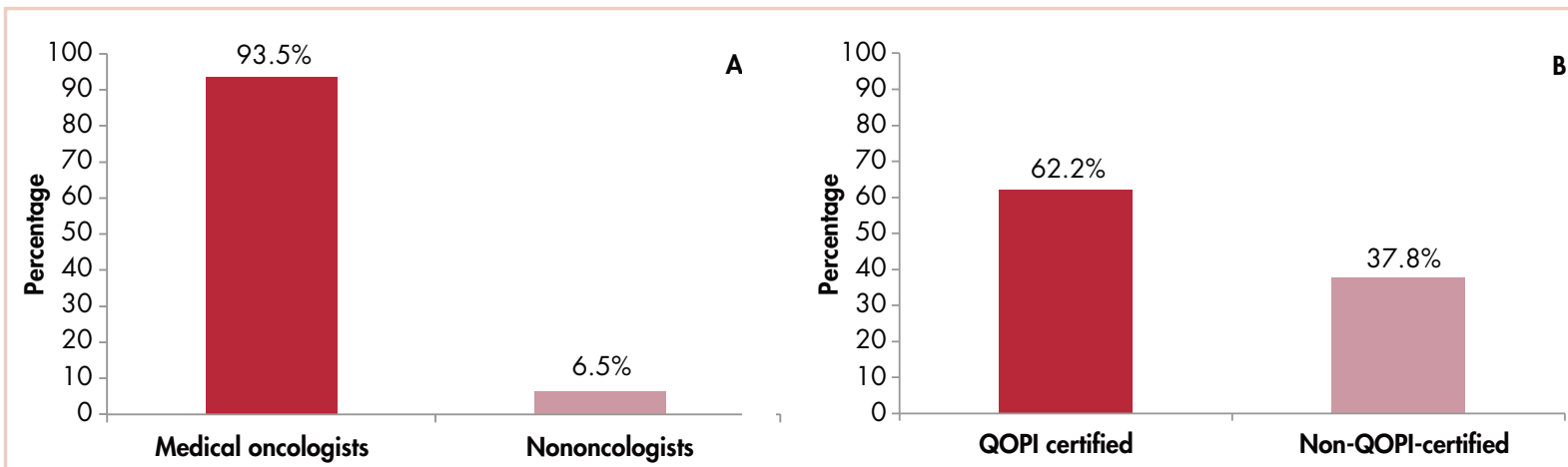

FIGURE 2 Proportion of respondents by A, specialty and B, QOPI certification QOPI, Quality Oncology Practice Initiative

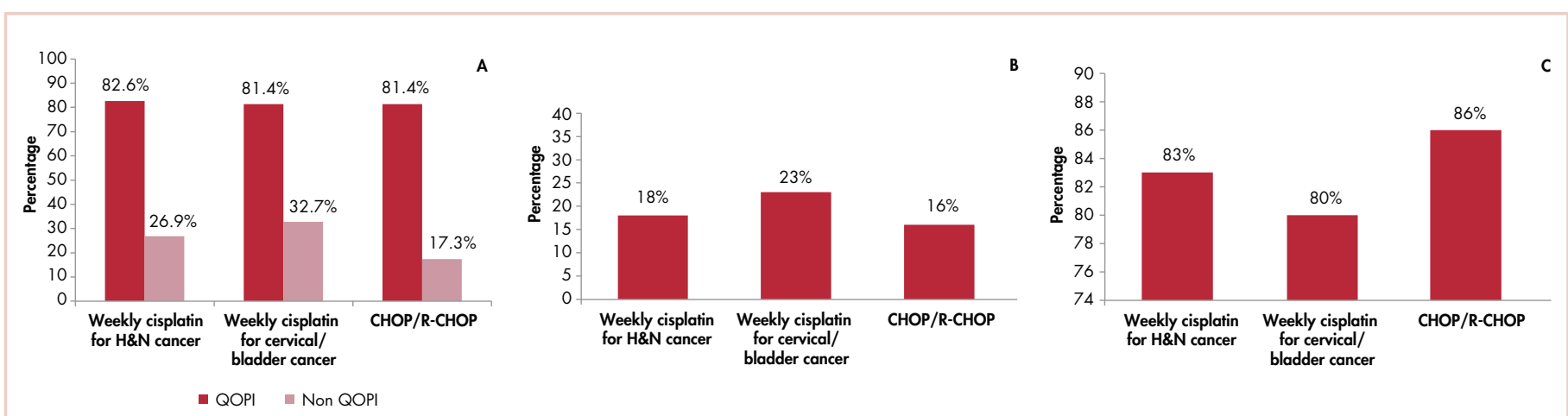

FIGURE 3 Proportion of A, oncologists using NK-1 antagonists with various low/moderate emetogenic regimens and B, QOPI-certified prescribers who felt NK-1 antagonists were necessary with these regimens, and C, QOPI-certified prescribers who prescribe NK-1 antagonists for the sole purpose of maintaining QOPI certification.

CHOP, cyclophosphamide, hydroxydaunorubicin, oncovin, and prednisone; NK-1, neurokinin 1; QOPI, Quality Oncology Practice Initiative; R-CHOP, rituximab + CHOP

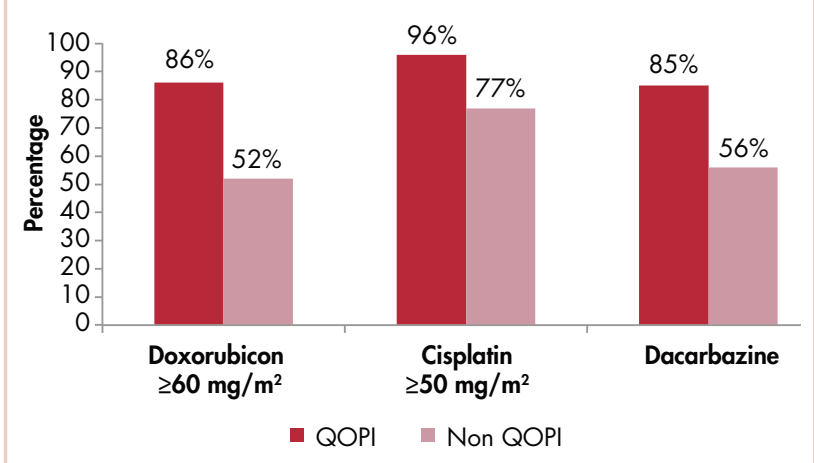

FIGURE 4 Proportion of oncologists who felt NK-1 antagonists were necessary with highly emetogenic regimens.

NK-1, neurokinin 1; QOPI, Quality Oncology Practice Initiative

rubicin $\geq 60 \mathrm{mg} / \mathrm{m}^{2}$, or dacarbazine. Doxorubicin, at dose of $60 \mathrm{mg} / \mathrm{m}^{2}$, is frequently used in the treatment of young women with breast cancer who are at high-risk for chemotherapy-related nausea and vomiting. ${ }^{17-19}$

Noncertified practitioners were presented with an abbreviated form of the survey, which contained identical ques- tions that asked about NK-1 receptor antagonist use in the same clinical settings.

The data from the surveys were analyzed in aggregate using likelihood ratio chi-square tests. $P$ values of $<.05$ are reported as significant. Descriptive statistics are used to describe the differences between groups.

\section{Results}

In all, there were 155 unique survey responses for a response rate of 23.8\%. Most of the respondents identified themselves as medical oncologists (145/155, 93.5\%, Figure 2 ) and went on to complete the survey. Nearly two-thirds (62.2\%) of the respondents were from QOPI-certified oncology practices (89/143, Figure 2).

Providers from QOPI-certified practices were significantly more likely to prescribe NK-1 receptor antagonists in conjunction with moderately emetogenic regimens than were providers from non-QOPI practices. In the setting of weekly cisplatin for head and neck cancer, $82.6 \%$ of practitioners from QOPI-certified practices used these agents, compared with $26.9 \%$ from noncertified practices $(P<.001)$. Similar patterns were observed with weekly 
cisplatin for cervical and bladder cancer $(81.4 \%$ vs $32.7 \%$, $P<.001)$ and with $\mathrm{CHOP} / \mathrm{R}-\mathrm{CHOP}(81.4 \%$ vs $17.3 \%$, $P<.001$, Figure 3).

When asked about their rationale for using these agents, a majority of the certified respondents replied that they used them to maintain their QOPI certification (80\%$85.7 \%$, Figure 3). When asked if aprepitant and fosaprepitant were clinically indicated in these settings based on their clinical judgment and/or personal experience, only a minority of certified respondents replied affirmatively (17.3\%-32.7\%, Figure 3). Weekly cisplatin for the treatment of bladder or cervical cancer received the strongest endorsement from the QOPI-certified physicains, whereas $\mathrm{CHOP} / \mathrm{R}-\mathrm{CHOP}$ was the regimen they felt least compelled to use.

Finally, we inquired about the use of these agents in the setting of highly emetogenic chemotherapy regimens, in which the use of NK-1 receptor antagonists is indicated because of their high emetic potential. In all cases, providers from QOPI-certified practices were more likely to prescribe these agents than were providers from non-QOPI practices (85.0\%-96.0\% vs $51.9 \%-76.9 \%$, respectively; $P<.001 ;$ Figure 4$).$

\section{Discussion}

Our data demonstrate that providers from QOPI-certified practices were significantly more likely to prescribe NK-1 receptor antagonists than were those in noncertified practices. Of note is that the certified physicians reported that satisfying the ASCO-QOPI requirements was their primary motivation for offering the agents. This may be due, at least in part, to the relatively low incidences of grade $3 / 4$ nausea and vomiting associated with the moderately emetogenic chemotherapy regimens discussed here.

Several limitations should be considered when inter-

\section{References}

1. Hesketh PJ. Chemotherapy-induced nausea and vomiting. N Engl J Med. 2008;358:2482-2494.

2. Hesketh PJ, Kris MG, Grunberg SM, et al. Proposal for classifying the acute emetogenicity of cancer chemotherapy. J Clin Oncol. 1997;15:103-109.

3. Gralla RJ, Osoba D, Kris MG, et al. Recommendations for the use of antiemetics: evidence-based, clinical practice guidelines. American Society of Clinical Oncology. J Clin Oncol. 1999;17:2971-2994.

4. Kris MG, Hesketh PJ, Somerfield MR, et al. American Society of Clinical Oncology guideline for antiemetics in oncology: update 2006. J Clin Oncol. 2006;24:2932-2947.

5. Basch E, Prestrud AA, Hesketh PJ, et al. Antiemetics: American Society of Clinical Oncology clinical practice guideline update. J Clin Oncol. 2011;29:4189-4198.

6. ASCO Institute for Quality: Quality Oncology Practice Initiative (QOPI). http://www.instituteforquality.org/quality-oncology-practice-initiative-qopi. Published/released January 2006. Accessed May 20, 2016.

7. ASCO Institute for Quality: QOPI certified practices. http://www. instituteforquality.org/qcp/certified-practices No last-update date given. Accessed May 20, 2016. preting these results. First, as with any survey-based assessment, practitioners with strong opinions may be more likely to participate than those with neutral opinions. This response bias may detract from the generalizability of our findings to the general population of medical oncologists. Second, although our conclusions were statistically significant, our dataset included only 155 responses (out of some 13,000 practicing medical oncologists nationally). Consequently, the views presented may not accurately reflect the sentiments of the national medical oncology community. Third, the brevity of our survey prevented us from collecting meaningful information about demographics and clinical judgment (academic or private, clinical scenarios when clinicians feel these agents are necessary, and so on).

Despite those limitations, we hope that our work will stimulate a productive discussion on the usage of these agents in clinical practice. In this era of emerging targeted therapies, many of which are capable of altering the natural history of a disease, our patients are on track to receive more lines of chemotherapy than ever before. The excitement for these agents, however, has been tempered by public outcry over their price. As Kantarjian and his colleagues have noted, the price of treatment has climbed logarithmically since 2000. Before then, a year of antineoplastic therapy cost less than $\$ 10,000$, but by 2012 , the 12 or 13 new drugs approved that year carried an annual price tag of more than $\$ 100,000$ per patient receiving them. ${ }^{20}$ Patients who fail these agents eventually receive second- and thirdline therapies, each with an additional layer of cost, resulting in burgeoning health care expenditures that are not sustainable. We as providers of cancer care must endeavor to temper quality of care with cost-conscientious health care. And above all, we cannot and should not ignore our clinical judgment.

8. ASCO Institute for Quality: Measures overview. http://www. instituteforquality.org/qopi/measures. No last-update date given. Accessed May 20, 2016.

9. Choosing Wisely: an initiative of the ABIM Foundation. http:// www.choosingwisely.org/wp-content/uploads/2015/02/ASCOChoosing-Wisely-List.pdf. Last updated October 29, 2013. Accessed May 20, 2016.

10. Micromedix Solutions: web applications access. http:// www.micromedexsolutions.com/micromedex $2 /$ librarian/ CS/214D05/ND_PR/evidencexpert/ND_P/evidencexpert/ DUPLICATIONSHIELDSYNC/0AED2B/ND_PG/evidencexpert/ND_B/evidencexpert/ND_AppProduct/evidencexpert/ND_T/ evidencexpert/PFActionId/evidencexpert.DoIntegratedSearch?Sear chTerm $=$ aprepitant\&UserSearch Term $=$ aprepitant $\&$ SearchFilter=filt erNone\&navitem=searchALL\#. No last-update date given. Accessed May 20,2016.

11. Coiffier B, Lepage E, Briere J, et al. CHOP chemotherapy plus rituximab compared with CHOP alone in elderly patients with diffuse large-B-cell lymphoma. N Engl J Med. 2002;346:235-242.

12. Lenz G, Dreyling M, Hoster E, et al. Immunochemotherapy with rituximab and cyclophosphamide, doxorubicin, vincristine, and pred- 


\section{Original Report}

nisone significantly improves response and time to treatment failure, but not long-term outcome in patients with previously untreated mantle cell lymphoma: results of a prospective randomized trial of the German Low Grade Lymphoma Study Group (GLSG). J Clin Oncol. 2005;23:1984-1992.

13. Valle J, Wasan H, Palmer DH, et al. Cisplatin plus gemcitabine versus gemcitabine for biliary tract cancer. N Engl J Med. 2010;362:1273-1281.

14. Gupta T, Agarwal JP, Ghosh-Laskar S, Parikh PM, D’Cruz AK, Dinshaw KA. Radical radiotherapy with concurrent weekly cisplatin in loco-regionally advanced squamous cell carcinoma of the head and neck: a single-institution experience. http://www.ncbi.nlm.nih.gov/ pmc/articles/PMC2702367/. Published online only June 15, 2009. Accessed May 19, 2016.

15. Rose PG, Bundy BN, Watkins EB, Thigpen JT, Deppe G, Maiman $\mathrm{MA}$, et al. Concurrent cisplatin-based radiotherapy and chemotherapy for locally advanced cervical cancer. N Engl J Med. 1999;340:1144-1153.

16. Hagan MP, Winter KA, Kaufman DS, et al. RTOG 97-06: initial report of a phase I-II trial of selective bladder conservation using TURBT, twice-daily accelerated irradiation sensitized with cisplatin, and adjuvant $\mathrm{MCV}$ combination chemotherapy. Int J Radiat Oncol Biol Phys. 2003;57:665-672.

17. Roila F, Tonato M, Basurto C, Bella M, Passalacqua R, Morsia D, et al. Antiemetic activity of high doses of metoclopramide combined with methylprednisolone versus metoclopramide alone in cisplatin-treated cancer patients: a randomized double-blind trial of the Italian Oncology Group for Clinical Research. J Clin Oncol. 1987;5:141-149.

18. Tonato M, Roila F, Del Favero A. Methodology of antiemetic trials: a review. Ann Oncol. 1991;2:107-114.

19. The Italian Group for Antiemetic Research [No authors listed]. Delayed emesis induced by moderately emetogenic chemotherapy: do we need to treat all patients? Ann Oncol. 1997;8:561-567.

20. Kantarjian H, Steensma D, Rius Sanjuan J, Elsshaug A, Light D. High cancer drug prices in the United States: reasons and proposed solutions. http://jop.ascopubs.org/content/10/4/e208.long. Published online only May 6, 2014. Accessed May 19, 2016. 